While this column allows all of us an opportunity to share our experiences and expertise in readers' advisory services, it isn't often that I share my thoughts will all of you. Your contributions are welcome and provide such a wealth of knowledge, lessons-learned, and best practices that I seek to offer this column as an opportunity for all of you to learn from each other. In this issue, I decided to write about something that has been in my mind for quite some time. With ever-changing technology and a growing market of e-readers, tablets, mobile devices, and interactive platforms, has our definition of reading changed? As I sit here and write this article, I am in the final weeks of teaching a reading and reading practices course to graduates in the School of Information Management program at Dalhousie University. This is something my students and I have been discussing over many weeks. But it isn't just a reflection on what is happening in the classroom. When I read electronic books with my three-year-old daughter, I have the option of reading the text to her, but video and sound effects are embedded within the story. If the narrator reads, the story becomes even more interactive. She can talk to the book and it responds. If she touches the screen, the characters move. This is far beyond the traditional concept of reading, yet, to my daughter, this is a form of reading that she will grow up with. While each of us must consider how we define reading and what a reader is, I hope that this article provides some

\title{
Laurel Tarulli
}

Laurel Tarulli (laureltarulli@yahoo.com) is instructor, School of Information Management, Dalhousie University, Halifax, Nova Scotia, and editor of the RUSQ Readers' Advisory column. thought on exploring traditional definitions and ideas around reading, the reader, and pleasure reading.-Editor

\section{I}

've taken on a new challenge this past January. At the beginning of the new year, I began teaching a reading and reading practices course at Dalhousie University. With my background in readers' services, practical experience, and attendance at numerous readers' advisory conference sessions, webcasts, and talks, I knew I was up for the challenge. However, devoting twelve weeks to the theory of reading, reading behaviours and models, practices in readers' services, and more, I realized that the learning opportunities provided to practicing professionals on reading and reading practices only manage to capture the top of the reading iceberg. Why do I compare reading, readers, and readers' advisory services to an iceberg? Icebergs seem relatively simple and straightforward when viewed from the shore or the deck of a boat. They are recognizable, easy to identify and navigate around, and appear-ahem-harmless. But we know better. Lurking beneath the water is a massive, complex, and unseen mass of ice much larger and difficult to navigate than what we observe on the surface.

Unfortunately, in our busy professional lives, the one-hour 
webinar or two-day readers' advisory course offered by our library systems are often the only formal training opportunity we have to expand our skills and find out about to new ideas or resources. In essence, we are only glimpsing the top of the iceberg. But what if we had the chance to think about, consider, and theorize as students do? What if we had twelve weeks to devote to learning about reading, readers, and readers' advisory services?

As I sit here writing this article, I am halfway through the semester and am taking the opportunity to reflect on key points and issues we've discussed in class. Trying to narrow down the topic for this article has been difficult. With such a wealth of rich information and theory to explore (that hulking mass of iceberg that lies beneath the surface of the water), I've decided that some of the easiest questions are often the most difficult to answer. As such, I've decided to explore the idea of reading, readers, and what, in this age of technology, defines pleasure reading. How do we determine what is pleasure reading when there is such a mash-up of formats and reading opportunities? The goal of this article is to examine the definition of what a reader is and to challenge the traditional definition of a reader. In addition, I will seek to push the boundaries of pleasure reading, briefly touching on the shortcomings and strengths of our current readers' advisory tools to address different forms of pleasure reading. Finally, considering perhaps a new definition of reader and pleasure reading, a brief exploration as to whether pleasure reading is declining will be presented.

\section{SEEKING A NEW DEFINITION OF READING AND PLEASURE READING}

\section{"I'm not a reader!"}

We often hear this from friends and family members who don't like to read books. But what makes a reader? What do we define as reading? Do you have to read books to be considered a reader?

As readers' advisors, we are put to the task of suggesting titles to readers who enjoy an ever-growing number of genres for both fiction and nonfiction. We rely on experience and knowledge, as well as print and web-based tools to help guide us in providing suggestions that offer options to our readers. But how often do we reflect on the definition of a reader and what constitutes pleasure reading? Do we include this in our staff training and manuals, or is it something we take for granted: pleasure readers read fiction or nonfiction books and we seek to connect each reader with another great read.

\section{IS THAT NECESSARILY ACCURATE?}

Let's take a look at some scenarios. For example, Iris considers herself an avid reader. Two of her favorite authors are Rosamunde Pilcher and Maeve Binchy. Never having learned to read, she listens to books and absorbs the reading experience aurally. Eddie, on the other hand, can't remember the last time he read a book. As a self-proclaimed nonreader, he is busy with work and family. In his spare time, he enjoys articles in gardening magazines and on home-improvement websites. Meanwhile, Clara loves to play video games. Her favorites are the ones that require reading scenarios and storylines to choose the path to the next level of the game. She enjoys the description of the characters and plots provided within the game, which enhance her experience.

In each of these scenarios, we can make arguments for and against applying the term "reader" to the individuals. Is Clara, a video game player, not a reader? What about her identification of the appeal of characters and rich plots (in text form) found within the games? Does that count? Can we not identify that Clara is a reader and her interaction with the text found in games as pleasure reading? And Eddie, the self-proclaimed nonreader? He is one of the most common readers we come across. Does pleasure reading and the definition of a reader come from the experiences we receive only through books? And then there's Iris, who is illiterate yet experiences the full enjoyment of a book through a different sense.

All of us may have different ideas about the above scenarios. In fact, when I asked my reading and reading practices class, which consists primarily of second year graduate students, it was unanimously agreed that Eddie and Iris meet the criteria of a reader. However, the class was divided in its opinion of defining Clara as a reader.

This raises the question, what is a reader? In these changing times where new formats are being introduced into the publishing industry and we're seeing e-books that incorporate videos, maps, interactive gaming techniques, and webcasts into the texts, do we need to redefine the meaning of what it is to read?

First, we need to explore what we mean by reading. Peter's identifies reading as an "umbrella term encompassing a wide variety of human behaviors." The examples that are given range from studiously examining large tomes to rapidly skimming citations, references, or any type of full text that piques our interest. ${ }^{2}$ Reading, therefore, can represent an interaction with text in a variety of formats for a variety of purposes. Taking this further, we can examine what it means to read, the act of reading, and the definition of pleasure by referring to the dictionary. Perhaps this is simplifying matters, but it can be useful. Dictionary.com defines the term read as a verb. In particular, it says that to read is "to look carefully so as to understand the meaning of . . . to utter aloud or render in speech ... to apprehend the meaning of (signs, characters, etc) otherwise than with the eyes ... and to apprehend or interpret the meaning of (gestures, movements, signals or the like)." " This takes into consideration interaction beyond the scope of text but also considers the use of additional sensory skills such as observation and tactile experiences. To read, therefore, provides us with knowledge or the ability to interact with the tangible or intangible and to interpret our experiences into meaning. When examining the definition of reading, Dictionary.com uses phrases such as "the action or 


\section{READERS' ADVISORY}

practice of someone who reads" and words like "interpretation." While we're all familiar with the term "pleasure," we can round out the traditional meaning of the term by once again referring to the dictionary. When defining pleasure, we observe words such as "enjoyment," "satisfaction," "recreation," "amusement," and "diversion."

Looking back at the scenarios mentioned earlier, we can start to make an argument that readers can no longer be identified solely as those who read fiction and nonfiction books, but need to include those who read magazines, websites, blogs, and video games. Indeed, Penguin is already creating ebooks that attract gamers because of their interactive gaming element. ${ }^{6}$ In these e-books, readers can follow the geographic routes that the characters travel and are able to interact with text and the storyline.

Duncan Smith, in his article "Your Brain on Fiction," determines that the experience of reading fiction is an ecological relationship between the reader and the book. As such, each reader will have a unique response to a book. ${ }^{7}$ If a reader develops a relationship with the text found within a magazine, a video game, or a blog, do we have the ability to disregard that relationship? Simply put, as readers' advisors, are we the ones that decide what constitutes reading for our patrons, adhering to a strict and traditional definition of reading and reader? Or do we listen with an open mind to our patrons and let them inform us about how they read and what they are reading?

As readers' advisors, many of us have already encountered the changing needs and interests of our readers. Eager to start their own career as librarians and readers' advisors, my students have found it challenging to move beyond the practice of recommending books outside of their familiar genres, never mind understanding the increasing challenges readers' advisors face in an age of new reading styles, preferences and formats.

\section{THE RA INTERVIEW}

In "Reinventing Readers' Advisory," Duncan Smith provides insight into the readers' advisory interview that will assist us when navigating these challenges. But first, I want to tell you a story about a recent phone conversation I had with Duncan. He was speaking to my class, and while talking about RA interviews, he was trying to impress on the students the difficulty we have in listening to our readers and the importance of listening. Duncan then asked me what book I was currently reading. I named a book and then launched into a bit of an explanation. When I was done, Duncan said he was simply waiting for me to stop talking so that he could tell me the name of the book he was reading. How many of us are guilty of that? Of not listening but of thinking we already know the answers or next great book suggestion when our readers' are asking for our assistance?

According to Smith, studies provide evidence that the interaction between readers and staff is more valuable than whether the patron receives the correct or appropriate answer.
Indeed, patrons are more likely to return to staff members with whom they had a positive experience, where they were able to share their reading experience(s). Readers' advisory, therefore, involves a deeper understanding of the "user's psyche." Basing our practices on this premise, we are well positioned to welcome new forms of reading, listening to our readers' and what reading characteristics they display. Listening to a gamer's love of rich text within games and the interactive quality found therein provides insight into recommending the new reading features in e-books, focusing on topics beyond that found in video games but with the same appeal factors.

As we acknowledge that pleasure reading includes the interaction with text as well as other senses such as touch, sound, and observation to create experiences in ways not previous considered, we can begin to push the boundaries of traditional reading practices and explore how and what to suggest for nontraditional readers.

One weakness, perhaps, in this period of transition will be the inability to rely on our current RA tools. While appeal terminology will still apply to many of the experiences found outside of the traditional reading experiences, it will have to be expanded to capture additional emotions and interactive qualities. Indeed, appeal will need to address suggestions of nontraditional titles and formats rather than simply books. This will result in a challenging time for all of us, when the reliance upon listening to our readers and valuing their experiences will become increasingly important.

While focussing on the growth of RA services in different formats such as music, film, and audiobooks, Trott indicates that readers' advisors will be faced with the challenge of applying RA practices and appeals to different formats over the next twenty-five years. ${ }^{9}$ Indeed, this is a reality!

\section{READING AT RISK OR READING ON THE RISE}

Taking into consideration the thoughts presented previously, we can start to challenge the assumption that reading is on the decline and reading for pleasure continues to decrease. Indeed, if we refer back to Peters' article, while reading purists may conclude that the rise of e-books, audiobooks, electronic games, and reading online indicates the beginning of the end of true reading, the librarians should delight in the growth of reading and a rebirth of reading that we could never have imagined in previous years. ${ }^{10}$ Interestingly, when discussing a recent literacy report in Canada, which indicates that pleasure reading is on the decline in elementary students, a question arose as to what the definition of pleasure reading included, how the questions were posed to the students, how the questions were phrased, and who asked the questions. For my students, the environment and situational factors of how the study was conducted were of extreme interest as they pointed out that, for any age group, how we behave and answer questions is often based on our environment and what we think is the right answer for that situation. Indeed, 
elementary students who have trouble reading or aren't sure of the definition of reading (comic books/graphic novels vs. fiction) might, indeed, consider themselves nonreaders, taking no pleasure in reading. How many of our recent studies rely on a purist definition of reading?

In fact, there may be reason to celebrate that reading is on the rise and that pleasure reading is a frequent and enjoyable experience that is increasing. It is only our traditional definitions of reading that need to be expanded to allow us to embrace the change and celebrate the growth of pleasure reading.

\section{CONCLUSION}

While reflecting on my teaching experiences, I have had to challenge my own definitions of reading and pleasure reading. I've encountered e-books that no longer reflect traditional reading practices but incorporated video, interviews, and interactive storylines that expanded my experience beyond my imagination. Through my students' eyes, I have been exposed to a variety of definitions of reading and have come to realize that reading, as most of us define it, is no longer as simple as it once was.

Although it is difficult to create one perfect definition or definitions for the terms read, reading, and pleasure reading, we can certainly begin to understand Peters' view of reading as "an umbrella term encompassing a wide variety of human behaviors" and that "the boundaries and varieties of reading experiences continue to expand and evolve."

\section{References}

1. T. Peters, "The Future of Reading," Library Journal 134, no. 18 (2009): 19.

2. Ibid.

3. Dictionary.com, "Read," accessed February 28, 2014, http://dictionary.reference. $\mathrm{com} /$ browse/read?s=t.

4. Dictionary.com, "Reading," accessed February 28, 2014, http:// dictionary.reference.com/browse/reading?s=t.

5. Dictionary.com, "Pleasure," accessed February 28, 2014, http:// dictionary.reference.com/browse/pleasure?s=t.

6. Jeremy Ettinghausen, "Beyond E-books: The Future of Digital Storytelling," YouTube video, 2010, accessed February 28, 2014, www.youtube.com/watch?v=BlEoFt7ty0Q.

7. Duncan Smith, "Your Brain on Fiction," Reference \& User Services Quarterly 49, no. 1 (2010): 39-42.

8. Ibid., 68

9. Barry Trott, "Building on a Firm Foundation: Readers' Advisory Over the Next Twenty-Five Years," Reference \& Users Services Quarterly 48, no.2 (2008), accessed February 28, 2014, http:// blog.rusq.org/2009/03/29/building-on-a-firm-foundation-read ers-advisory-over-the-next-twenty-five-years.

10. Peters, "The Future of Reading," 18.

11. Ibid., 19. 